\title{
A QUESTÃo QUILOMBOLA NO CURRÍCULO DA EPT: POR UMA EDUCAÇÃO OMNILATERAL
}

\author{
Diego dos Santos Alves ${ }^{1}$ \\ Beatriz Medeiros de Melo
}

\section{RESUMO}

O presente artigo investiga o lugar da questão quilombola no currículo do ensino de História na Educação Profissional e Tecnológica (EPT), mediante as percepções e práticas de estudantes e professores do Instituto Federal de Alagoas (Ifal). Integrando uma pesquisa em desenvolvimento em nível de mestrado, a reflexão ancora-se metodologicamente na abordagem qualitativa, com aporte no método da pesquisa-ação e na técnica da Análise de Conteúdo. Nesse percurso, examina a relação entre o ensino de história e a formação integrada, e identifica a ausência da questão quilombola no currículo integrado. Apresenta, ainda, a construção do Produto Educacional vídeo educativo como recurso de inclusão da memória quilombola, contribuindo para a garantia de uma formação omnilateral, no horizonte da EPT.

Palavras-chave: Quilombolas; Formação integrada; Currículo; Ensino. Educação Profissional e Tecnológica.

\section{THE QUILOMBOLA ISSUE IN THE EPT CURRICULUM: FOR OMNILATERAL EDUCATION}

\begin{abstract}
This article investigates the place of the quilombola issue in the history teaching curriculum in Professional and Technological Education (EPT), through the perceptions and practices of students and teachers of the Federal Institute of Alagoas (Ifal). Integrating research in
\end{abstract}

\footnotetext{
${ }^{1}$ Licenciado em História pela Universidade Federal de Alagoas (2008). Acadêmico do curso de mestrado profissional em Educação Profissional e Tecnológica - ProfEPT no Instituto Federal de Alagoas. Professor do Instituto Federal de Educação, Ciência e Tecnologia de Alagoas, Campus Santana do Ipanema. diego.alves@ifal.edu.br

${ }_{2}$ Doutora em Sociologia pela Universidade Federal de São Carlos. Docente Permanente no Programa de Mestrado Profissional em Educação Profissional e Tecnológica ProfEPT no Instituto Federal de Educação, Ciência e Tecnologia de Alagoas, Campus Viçosa. Docente Colaboradora no Programa de Mestrado em Sociologia da Universidade Federal de Alagoas. Vice-coordenadora do Grupo de Pesquisa do CNPq Terra, Trabalho, Memória e Migração. beatriz.melo@ifal.edu.br
} 
development at the master's level, the reflection is anchored methodologically in the qualitative approach, with input in the method of action research and the technique of Content Analysis. Along this path, it examines the relationship between history teaching and integrated training, and identifies the absence of the quilombola issue in the integrated curriculum. It also presents the construction of the Educational Product educational video as a resource for the inclusion of quilombola memory, contributing to the guarantee of omnilateral training, within the EFA horizon.

Keywords: Quilombolas; Integrated training; Curriculum; Teaching; Professional and Technological Education.

\section{INTRODUÇÃO}

O presente texto visa investigar a presença da questão quilombola no ensino de História no currículo da Educação Profissional e Tecnológica, a partir da realidade observada no Instituto Federal de Alagoas (Ifal). A investigação é parte de um esforço de compreensão acerca da concretização do princípio da educação omnilateral, assumido como princípio orientador das práticas educativas, extensionistas e de pesquisa no âmbito dos Institutos Federais desde 2008 (Lei 11.892/2008). A pesquisa é conduzida, ainda, em direção à produção de um produto educacional no âmbito do Mestrado Profissional em Educação Profissional e Tecnológica.

Nesse percurso, assumimos os pressupostos metodológicos da abordagem qualitativa, por considerá-la privilegiada para a apreensão dos sentidos e significados construídos pelos atores no processo educacional, possibilitando uma percepção do contexto histórico e social da coletividade escolar (MINAYO, 2002). Assim, dentro da abordagem qualitativa, adotamos os princípios da pesquisa-ação, considerada por Thiollent (1986) como uma via que encaminha soluções para problemas coletivos. Ressaltamos, desse modo, o caráter dual da pesquisa-ação: de um lado, atua para a intervenção na realidade pesquisada, visando transformá-la; de outro, visa concretizar tais mudanças a partir da participação dos atores que compõem a situação investigada. Nesse sentido, este trabalho, particularmente, encontra-se perpassado por percepções e práticas de 30 docentes e 31 discentes do Instituto Federal de Alagoas (Ifal), registradas por meio de questionários fechados e entrevistas semiestruturadas. 
O material foi coletado durante o período de isolamento ensejado pela pandemia de Covid-19, a partir das plataformas digitais Google Forms e Google Meet, tendo adotado o instrumento metodológico da análise de conteúdo (BARDIN, 2011) para a leitura e interpretação dos dados.

O texto estrutura-se em cinco seções, incluindo esta introdução. Na segunda seção, retomamos os princípios de formação integrada, politécnica e omnilateral para pensar criticamente o ensino de História, como canal para a valorização da história e experiência quilombola, na contramão da invisibilidade a que tais grupos foram lançados no decurso histórico brasileiro. Em seguida, examinamos as re-existências quilombolas no Brasil e em Alagoas, que tomam forma nas comunidades remanescentes, e refletimos a ausência desse debate no contexto do currículo integrado, na EPT. Na quarta seção, apresentamos o vídeo educativo, como recurso didático, para repensar o ensino de História, em sintonia com a construção de uma educação antirracista. Reservamos a quinta seção para as considerações finais.

\section{O ENSINO DE HISTÓRIA E A EDUCAÇÃO INTEGRAL NA EPT}

No horizonte da Educação Profissional e Tecnológica, a garantia do acesso das classes menos favorecidas à educação intelectual permanece um desafio, diante do histórico nacional de (con) formação exclusiva para a vida produtiva. Nesse sentido, consolidar uma proposta contra-hegemônica que, em vez de agravar a alienação da classe trabalhadora, caminhe na direção de uma perspectiva humanizada e humanizadora, construída na convergência de educação e trabalho, é um desafio e uma demanda importante na construção de um projeto de sociedade de mais justiça social. Nesse sentido, o pensamento de Gramsci (1998) possibilitanos pensar um modelo de Ensino Médio Integrado baseado no conceito de escola unitária:

A escola unitária ou de formação humanista ou de cultura geral deveria se propor a tarefa de inserir os jovens na atividade social, depois de tê-los levado a certo grau de maturidade e capacidade, à criação intelectual e prática e a certa autonomia na orientação e na iniciativa. Do ensino quase puramente dogmático, no qual a memória desempenha um grande papel, passa-se à fase criadora ou de trabalho autônomo e independente; da escola com disciplina de estudo imposta e controlada autoritariamente passa-se a uma fase de estudo ou de trabalho profissional na qual a autodisciplina 
intelectual e a autonomia moral são teoricamente ilimitadas (GRAMSCI, 1998, p. 114).

O ensino unitário de Gramsci (1998), trazido para a realidade brasileira, questiona a dualidade estrutural da educação, fundada na segmentação entre uma educação para a classe trabalhadora, limitada ao ensino técnico, instrumental, e uma educação para as elites, direcionada ao desenvolvimento intelectual. Percorrendo estas trilhas, a década de 80 simboliza um marco na história nacional, por ter abrigado intensos debates em torno da construção de um paradigma educacional progressista. Em meio aos enfrentamentos dos educadores brasileiros no período pós-Ditadura Civil Militar, Saviani (1989) retomou um termo vigoroso para o projeto de formação integrada, com o fito de universalizar o acesso dos brasileiros a bens universais como ciência e cultura, negados na lógica hegemônica e antiemancipatória do capital. Trata-se da politecnia, a qual "postula que o trabalho desenvolva, numa unidade indissolúvel, os aspectos manuais e intelectuais". Isto porque "todo trabalho humano envolve a concomitância do exercício dos membros, das mãos e do exercício mental, intelectual. Isso está na própria origem do entendimento da realidade humana, enquanto constituída pelo trabalho" (SAVIANI, 1989, p. 15).

Herdeiro destes esforços, o Ensino Médio Integrado dos Institutos Federais, afastandose da formação dual e elitista, desponta no Brasil democrático (2008) como proposta fundada no conceito de formação unitária, dilatando os sentidos e significados da formação básica. Frigotto, Ciavatta e Ramos (2005, p. 43), importantes expoentes na elaboração dos fundamentos desta proposta assumem que, se o ensino profissional nos surge como uma necessidade, é imperativo legal e ético "garantir que o ensino médio se desenvolva sobre uma base unitária para todos. Portanto, o ensino médio integrado ao ensino técnico, sob uma base unitária de formação geral, é uma condição necessária para se fazer a 'travessia' para uma nova realidade".

Dialogando com tais princípios, Nosella (2011) postula que garantir a travessia para outra vivência social implica ressignificar as formas de interação histórica entre homem e natureza, moduladas, nos últimos séculos, pelo modo de produção capitalista. Esse esforço enseja uma concepção humanista, para a qual, assumindo seu caráter histórico e ontológico, o trabalho abarque as relações sociais construídas em todos os níveis da vida do estudante, sem dizer respeito exclusivamente à sua função produtiva na sociedade cindida em classes, tendo 
como uma de suas bases a noção de trabalho como princípio educativo. Esta noção, desenvolvida por educadores brasileiros a partir de concepções marxistas e gramscianas, está fundada na necessária compreensão do vínculo indissociável entre trabalho (em sua acepção marxista ampla), produção de conhecimento (cultural, científico, tecnológico) e constituição do homem em sua materialidade e subjetividade (CIAVATTA, RAMOS, 2011). Aos jovens é preciso dar a conhecer essa intricada e importante relação, que empresta sentido a todas as expressões do trabalho, quer sejam alienantes ou emancipadoras.

Ante à tal proposta humanista, aventamos a aproximação com um certo ensino de História enquanto possibilidade de construção de sentidos que, por um lado, revelem as bases da produção de desigualdades de toda ordem. Falamos da História que afastou-se do positivismo científico, produzindo as bases legitimadoras, teóricas e metodológicas, para a utilização de novas fontes de pesquisa, validando, entre essas, a utilização da oralidade. $\mathrm{O}$ desenvolvimento da história oral, enquanto metodologia de pesquisa, criou novos horizontes para o trabalho de reconstrução das memórias sociais, possibilitando o trabalho historiográfico com as narrativas dos subalternos, excluídos, esquecidos, silenciados pela história oficial. Da perspectiva educacional, também concorrem para aproximar o aluno da multiplicidade de vozes e de experiências sociais:

O novo equilíbrio quanto ao conteúdo da história e às fontes de sua evidência alterará seu julgamento e, assim, finalmente, sua mensagem como mito público. Descobriremos no passado um conjunto diferente de heróis: gente comum, tanto quanto líderes: mulheres, tanto quanto homens; negros, tanto quanto brancos (THOMPSON, 1992, p. 335).

Nesse aspecto, o ensino de História assume também a tarefa de corrigir equívocos e silenciamentos do passado, indo ao encontro da afirmação de Ricoeur (2007, p. 101): "o dever de memória é o dever de fazer justiça, pela lembrança, a um outro que não o si”. Assim, essa História coloca-e à serviço de um projeto ético-político que pode colaborar para a superação do quadro de exclusão, discriminação e fragmentação dos sujeitos fragilizados social e historicamente, que ainda hoje enfrentam resistências para acessar direitos sociais basilares.

$\mathrm{Na}$ esteira da difusão dos trabalhos com a oralidade e do surgimento da corrente historiográfica da Nova História, viabilizada pela Escola do Annales, uma certa historiografia passa a olhar, ainda, para os universos locais e regionais, excluídos e 
silenciados das perspectivas histórico-científicas tradicionais, e do discurso de construção da nação. Acompanhando esse movimento, o ensino de História pode oferecer aos discentes uma concepção plural, diversa e ativa, que comporte novos atores e traga para o cotidiano escolar um olhar multicultural, capaz de "resgatar manifestações culturais de determinados grupos cujas identidades se encontram ameaçadas, (...) tornar o mundo menos opressivo e injusto, para a urgência de se reduzirem discriminações e preconceitos (MOREIRA, 2007, p. 30).

Em sintonia com o projeto de construir pontes com a realidade dos estudantes, com seus conhecimentos prévios e seus centros de interesse - conforme evoca Freire (1987) como premissa básica para uma formação crítica, ativa e reflexiva - o ensino da história local e regional desloca a orientação do macro para o micro, do discurso oficial para os discursos marginalizados, da hegemonia da história imutável para a história dinâmica e múltipla, que transcorre vivamente no cotidiano de todos nós, que se (re)faz entre realidades, paisagens e personagens negligenciados pela escola. "Ela [a História Local] é encontrada dobrando a esquina e descendo a rua. Ele pode ouvir os seus ecos no mercado, ler o seu grafite nas paredes, seguir suas pegadas nos campos (SAMUEL, 1990, p. 220).

Alcançando os substratos da memórias, as histórias subalternizadas, enterradas pelos que detêm o poder para manter o silenciamento de grupos sociais fragilizados, vêm à tona. Nesse contexto, o trabalho historiográfico e pedagógico com as memórias sociais põe em xeque o projeto de esquecimento de histórias que ainda resistem nos territórios brasileiros. $\mathrm{O}$ desafio de manter tais memórias vivas tem sido assumido por diversos pesquisadores e educadores do campo da história, que ao negar a cilada do anacronismo, busca no conteúdo do presente as conexões com o passado. Reconhecem, tal como em Halbwachs (2006, p. 86), que ao lado de uma história escrita há uma história viva, na qual se pode encontrar novamente um grande número dessas correntes antigas que desapareceram apenas em aparência (HALBWACHS, 2006, p. 86).

Na garantia de um ensino de História que assuma como premissa o desvelamento e superação das desigualdades, compromissos assumidos pela EPT no Brasil, podemos estabelecer um diálogo, então, com o conceito de história vista de baixo. Pensado pelo 
historiador inglês Edward Palmer Thompson ${ }^{3}$ (1998) como crítica às tendências marxistas estruturalistas, a concepção adverte para a consideração da experiência e da cultura como produtoras de sentido. Assim, abre espaço para a escuta das narrativas de trabalhadoras e trabalhadores, em sua rotina e seu particular modo de perceber e construir sentido, recorrentemente silenciados nos discursos oficiais e nos currículos. E, desse modo, contribui para compreender as formas de dominação e de resistência em sua diversidade de formas, desnaturalizando-as, no sentido apontado por Ramos (2015, p. 417).

Passadas quatro décadas, a proposta de uma formação integrada, assentada nos princípios da politecnia e da omnilateralidade, flutuou aos interesses das instâncias do Poder Executivo, que se revezaram na gestão federal e manifestaram compromissos diversos com o capitalismo financeiro internacional. A despeito disso, o projeto em torno de uma formação integrada, politécnica e omnilateral, ainda que com ressalvas e limites a serem considerados, é uma realidade, especialmente ao considerarmos a criação dos Institutos Federais, seu processo de interiorização e o amparo das politicas afirmativas, que ampliou o acesso dos filhos da classe trabalhadora à aludida proposta.

Apesar dos avanços, cabe-nos investigar em que medida as práticas educativas tem respeitado as concepções pedagógicas vinculadas à proposta de formação integrada. Diante disso, o olhar para as práticas curriculares assume uma relevância sui generis, ainda mais no âmbito da EPT, tendo em vista a necessidade de substituição da sua tradição de adestramento para as demandas do mercado, por uma práxis emancipatória, libertária e democrática. Nessa direção, emerge como categoria central de análise a noção de currículo integrado. A partir desta categoria, avançaremos na investigação do lugar da questão quilombola no currículo, enquanto elemento importante na construção de uma educação omnilateral.

\section{CURRÍCULO INTEGRADO E A QUESTÃO QUILOMBOLA: UMA AUSÊNCIA}

Entre os séculos XVI e XIX, atracaram nos portos brasileiros milhares de africanos, que atravessaram o Atlântico para abastecer o sistema colonial da América Portuguesa,

\footnotetext{
3 Considerado o maior historiador inglês do século XX, revolucionou a historiografia social inglesa, introduzindo o conceito de história vista de baixo, através do qual atribui protagonismo a classes dominadas e excluídas, como camponeses, operários e pessoas comuns.
} 
caracterizado pelas grandes propriedades de terra (latifúndios), pela monocultura e, em sua face mais perversa, pelo trabalho compulsório, um eufemismo para se referir ao vil processo de escravização. Subjugados, os escravizados foram vítimas de todos tipo de violência, desde a violência física, dos castigos e da exaustão pelo trabalho, a violência psicológica, da dissolução de vínculos parentais, da proibição de manifestações de crenças e outras práticas culturais... em suma, da negação da própria humanidade. E, no limite, compuseram a maior parte dos números "frios" de mortos no Brasil Colônia, em nome da produtividade e do lucro.

Diante das condições ultrajantes às quais foram submetidos, elaboraram uma série de estratégias para sobreviver e resistir à barbárie da sociedade escravista, a exemplo de motins, insurreições, assassinatos e fugas. Essas reações à escravidão assumiram ora um caráter violento, ora negociável. Nessa direção, estudos como os de Reis e Silva (2005) destacam o acentuado processo de negociação entre escravizados africanos e grandes proprietários rurais, como recurso para sobrevivência e inserção frente aos rearranjos sociais. Castilho (2018, p. 244) realça esse universo de negociações que atravessou o escravismo brasileiro, sobretudo no período pós-abolição, no qual "o cativo também aparece na condição de sujeito histórico e possuidor de espaços de autonomia”. Desse modo, em maior ou menor grau, esse conjunto de resistências, bem como a disseminação do ideário liberal propagado pela classe dos burgueses, foi minando o regime escravocrata.

Entre as expressivas manifestações de resistência dos escravizados, corporificaram-se as comunidades de fugitivos. Com organização política própria e base econômica caracterizada pela coletividade da produção, as comunidades quilombolas simbolizam um profícuo instrumento africano nos embates pela emancipação do povo negro. Embora as fugas tenham sido marcantes demonstrações das resistências de escravizados em toda América, o termo quilombo universaliza-se, notadamente, no Brasil. De origem africana, o termo que significa esconderijo foi incorporado à língua portuguesa tornando-se sinônimo de escravos fugidos (GENNARI, 2008, p. 71-72 apud SOUZA, 2012). Oficialmente, o termo dizia respeito à "toda habitação de negros fugidos, que passem de cinco, em parte despovoada, ainda que não tenham ranchos levantados e nem se achem pilões nele". Tal descrição era enunciada pelo Conselho Ultramarino, ao se reportar para a Corte Portuguesa. É essa definição, presente nos documentos oficiais, que marca o espaço do termo quilombo para os 
estudos das comunidades de resistência, ao menos até a década de 1970 (SCHMIDTT; TURATTI; CARVALHO, 2002). Assim, conforme recorda Silva (2013, p. 17), “quilombos e quilombolas foram interpretados pelos pesquisadores [...] como espaço singular da luta do povo negro pela liberdade".

De fato, o crescimento populacional dos quilombos, cuja reprodução, lembra Gomes (2015), acontece também internamente, desafia a estrutura escravista e desencadeia na sociedade senhorial uma tentativa de contrarrevolução. Nessa perspectiva, as estratégias de sobrevivência dos quilombolas passam a ser combatidas, seja por intermédio da figura dos capitães do mato, seja por meio da destruição das "cidades" quilombolas. Se por um lado, as perseguições representavam um risco iminente à manutenção e ampliação das comunidades fugitivas, por outro provocaram outras ações de resistência, em direção à conquista da liberdade dos escravizados, conforme destaca Marques (2020, p. 245):

A hegemonia senhorial, que procurou exercer sua dominação combatendo quilombos, revoltas e fugas, restringindo alforrias e proibindo as práticas culturais de matrizes africanas, deparou-se com uma forte e articulada resistência escrava, que também se configurou no campo da cultura. Reiventando suas identidades e desenvolvendo, dentro das possibilidades existentes, variadas estratégias para obter meios de subsistência e resistir à instituição escravista, a população africana e seus descendentes tiveram sempre a liberdade em seu horizonte.

Em parte do território de Alagoas erigiu-se o mais emblemático dos quilombos, o de Palmares. Sua representação diz tanto sobre a luta negra em prol da liberdade que, ao menos à luz dos livros didáticos, Palmares tornou-se sinônimo de quilombo. Em alguma medida, essa generalização empobrece o debate acerca das centenas de comunidades de fugitivos que se propagaram pelo país, nas zonas rural e urbana, obscurecidas nas narrativas que resumem a temática ao Quilombo dos Palmares. Por outro lado, tal fato nos auxilia a mensurar a importância da resistência palmarina "como um elemento dinâmico de desgaste das relações escravistas" (MOURA, 1993, p. 31). De fato, Palmares simboliza o maior abalo à estrutura escravocrata à nível regional, reverberando como modelo de resistência no resto do território brasileiro.

Findada a escravidão, seus efeitos podem ser considerados como definidores do lugar ocupado pelos descendentes de ex-escravizados no Brasil atual. As marcas de um passado 
escravizado, de condições subumanas e de exclusões produzidas e reproduzidas no pósabolição, à revelia do que defendem os projetos humanistas de sociedade, seguem determinando a invisibilização e exclusão negra no Brasil contemporâneo. Não obstante, da negação da cidadania à população negra, emana um emaranhado de discussões, a exemplo do reconhecimento de dívida histórica com a população negra, da necessidade de políticas afirmativas, da exigência de uma historiografia plural e contestatória, da busca por igualdade e justiça social.

A luta pelo direito à terra, pelo respeito à identidade e pela valorização históricocultural não findou e consta da agenda quilombola hodiernamente. Emancipadas com a Constituição de 1988, ao menos legalmente, as comunidades quilombolas foram desafiadas a remanescer num cenário em que os direitos básicos de cidadania lhes foram negados. Recriar sua cultura, história e identidade vem se configurando um desafio permanente, diante de reveses sistemáticos, que produziram ao longo da história um grave silenciamento às comunidades de resistência, tão relevantes para a construção da história brasileira. $\mathrm{Na}$ tentativa de preservar sua história, os ex-escravizados mantêm a resistência no Brasil do século XXI, organizados em comunidades remanescentes quilombolas, que "produziram histórias complexas de ocupação agrária, criação de territórios, cultura material e imaterial" (GOMES, 2015, p. 7).

Segundo Silva (2013) o novo conceito de comunidade remanescente quilombola representa uma ressignificação de possibilidades, deixando de servir exclusivamente à elucidação do processo de luta negra no Brasil, para comportar uma agenda de direitos civis e sociais destinados aos povos africanos e seus descendentes na Diáspora, reconhecidos pela manutenção da identidade e ancestralidade. Em Alagoas, estado em que se insurgiu a mais insubmissa e sólida comunidade quilombola da América Latina, subsistem 68 comunidades remanescentes, reconhecidas pela Fundação Palmares, de acordo com o sítio do Instituto de Terras e Reforma Agrária de Alagoas (Iteral). Mas, para além do reconhecimento desses territórios como comunidades remanescentes, o que sabemos a respeito dos quilombolas alagoanos? Eles estão retratados nos livros didáticos? Têm se empreendido esforços para a reconstrução da história e memória destas comunidades? Os saberes tradicionais tem perpassado o currículo e colaborado para práticas educativas antirracistas? 


\section{Figura 1 - Distribuição das comunidades quilombolas em Alagoas}

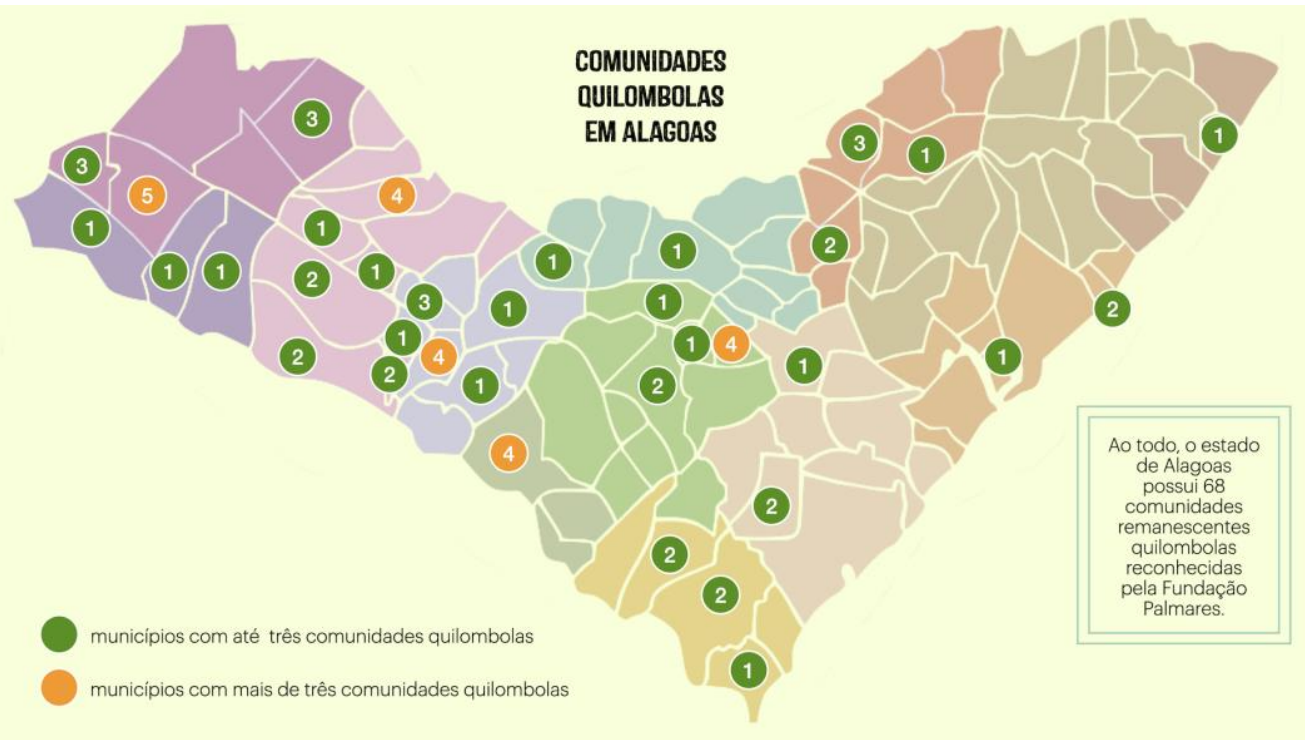

Fonte: Iteral (2020). Elaborado pelo autor.

Para responder a tais questões, valemo-nos das percepções de 30 professores de História e de 31 estudantes, do Instituto Federal de Alagoas. Desse universo pesquisado, 28 docentes registraram suas experiências por meio do questionário fechado aplicado via Google Forms, enquanto outros 2 participantes da pesquisa deram sua contribuição mediante entrevista semiestruturada, realizada via Google Meet. Todos os 31 estudantes são do campus do Ifal em Santana do Ipanema, matriculados na modalidade Ensino Médio Integrado e participaram da pesquisa mediante questionário fechado aplicado via Google Forms.

Tal investigação fez-se imprescindível a nossa pesquisa haja vista a necessidade de avaliar a efetiva construção de um currículo integrado. Comecemos essa reflexão com uma pergunta e uma definição: o que significa integrar? No Dicionário Priberam da Língua Portuguesa, o verbo integrar significa tornar inteiro, tornar-se parte de um conjunto ou de um grupo; incluir, incorporar. Trazido para o campo curricular, o verbo representa a possibilidade de ressignificar a prática fragmentada, compartimentalizada e mecanicista. Nessa lógica, o currículo integrado compreende o trabalho pedagógico como um todo e recusa a formação isolada de educandos parciais, pretendendo "desenvolver uma integração de campos de conhecimento e experiência que facilitem uma compreensão mais reflexiva e crítica da realidade (SANTOMÉ, 1998, p. 27). 
O conceito de currículo integrado é depositário dos estudos de Bernstein (1996), sociólogo inglês que critica as práticas pedagógicas fragmentadas. O currículo coleção, caracterizado pela separação do conhecimento em disciplinas sob rígido sistema de classificação, concebido em frações, é o ponto de partida crítico para Bernstein propor uma outra organização curricular. Nela, o autor articula o contexto social dos estudantes com seus interesses e demandas, procurando integrar os conhecimentos. Nessa concepção, as áreas fronteiriças dos conhecimentos separados em disciplinas passam a ser menos perceptíveis, uma vez que que os saberes misturam-se e integram-se (BERNSTEIN, 1996).

Assim, o currículo integrado não engloba apenas fragmentos da realidade humana, especialmente acerca do trabalho em seu sentido histórico, mas também ciência e cultura, garantindo aos trabalhadores o acesso a uma compreensão global do saber. Nessa direção, Paulo Freire advoga pela formação de homens e mulheres enquanto "corpos conscientes":

A educação que se impõe aos que verdadeiramente se comprometem com a libertação não pode fundar-se numa compreensão dos homens como seres "vazios" a quem o mundo "encha" de conteúdos; não pode basear- se numa consciência especializada, mecanicistamente compartimentada, mas nos homens como "corpos conscientes" e na consciência como consciência intencionada ao mundo. Não pode ser a do depósito de conteúdos, mas a da problematização dos homens em suas relações com o mundo. (FREIRE, 1987, p. 39).

Assumindo a perspectiva de integração em todas as suas modalidades, a Educação Profissional e Tecnológica visa legitimar uma proposta curricular que, fundamentada no trabalho como princípio educativo, valoriza o conhecimento não-fragmentário, global, articulado. A aprendizagem, sob esse prisma, transcende o saber que adestra, para pensar o homem em todas as potencialidades, o sujeito multilateral, expresso na concepção omnilateral em Marx (1983).

No lastro das discussões acerca do currículo integrado, Moreira (2003) lembra a importância de que o campo curricular compreenda e valorize os saberes excluídos, esquecidos, subalternizados, desconstruindo barreiras e preconceitos. Nesse sentido, considerando o Livro Didático como um importante elemento orientador dos currículos no cotidiano escolar, e, nesse sentido, também da presença da temática quilombola no currículo integrado, investigamos, mediante as experiências docentes, a realidade do Ifal. 
Nesse sentido, inicialmente, os professores apontam para o descumprimento da previsão legal, por parte do Estado, em produzir e prover as instituições de materiais didáticos específicos com a história e cultura quilombolas (BRASIL, 2004). Portanto, o fato de 68\% do corpo docente acenar para esse desrespeito à lei demonstra-nos que quebrar os silêncios históricos sobre os quilombolas constitui-se um desafio permanente. Contudo, para a maioria dos estudantes a questão quilombola, inserida na temática afro-brasileira e africana, tem sido contemplada nos Livros Didáticos. Ainda assim, o nível de reconhecimento estudantil sobre a realidade quilombola reforça a percepção dos docentes quanto à produção de silêncios nos materiais didáticos.

Nessa direção, apenas 6,5\% dos discentes afirmam conhecer amplamente a temática quilombola, enquanto $61,3 \%$ conhecem algo a respeito e $32,3 \%$ admitem conhecer pouco a temática, um forte indício do processo de invisibilização da temática frente à perspectiva eurocêntrica. Nesse sentido, pensando o currículo como uma das mais importantes ferramentas de mudança de padrões étnico-raciais desiguais, o campo do ensino de História deve assumir seu lugar crítico, contestatório, que nega as verdades absolutas e questiona o controle do poder.

A abordagem frágil e enviesada da temática parece se confirmar quando avaliamos qualitativamente a compreensão dos estudantes acerca das comunidades quilombolas. Nesse sentido, os testemunhos discentes relacionam tais comunidades, quase que de modo exclusivo, ao período da escravidão, legalmente findado em 1888. Tais percepções podem ser compreendidas como parte de um processo mais amplo, de negação da diversidade brasileira e de recusa às demandas quilombolas e indígenas na atualidade, com o Livro Didático compreendido como reprodutor desse mecanismo de dominação.

O desconhecimento da continuidade da resistência quilombola nas comunidades remanescentes soa ainda mais grave ante o dado de que 64,5\% dos discentes desconhecem as populações localizadas nos arredores das suas cidades, no sertão alagoano. A falta de ciência sobre a manutenção dos quilombolas no pós-abolição revela-se preocupante a partir do reconhecimento do contexto local, em que diversas comunidades remanescentes quilombolas já foram reconhecidas, pela Fundação Palmares, em municípios do entorno do campus do Ifal em Santana do Ipanema, lócus da pesquisa, como Poço das Trincheiras e Olho D’Águas das 
Flores. Reforça, ainda, o distanciamento entre a História regional e local com a formação recebida no contexto da EPT.

Apesar de demonstrarem domínio sobre o fenômeno contemporâneo dos quilombos remanescentes, os docentes, assim como os estudantes, afirmam não conhecer o contexto real das comunidades localizadas no sertão. Essa realidade acaba sinalizando um represamento de saberes, uma subutilização das tradições histórico-culturais da potente fonte mnemônica quilombola, uma restrição do compartilhamento das experiências e trajetórias negras, que poderiam desaguar na formação dos estudantes. Desse modo, compreendemos que a garantia legal de reconhecimento desses grupos sociais marginalizados, silenciados e excluídos, na e pela educação, continua se constituindo um óbice em tempos atuais.

Como compreender esse silenciamento? O que a escola tem feito para dar visibilidade à memória viva, que se desenlaça um sem-número de vezes ao lado das instituições de ensino? São questões que se impõem e que esse espaço não dá conta de responder. Ainda assim, dispomo-nos a refletir. Assim, a já reconhecida negação do negro na experiência afrodiaspórica brasileira têm peso ainda maior que no restante do território brasileiro, uma vez que a história sertaneja é a das trajetórias indígenas e quilombolas. Desse modo, os silêncios lançados sobre as populações negras sertanejas, alçadas à condição de invisíveis, seguem a reverberar no cotidiano quilombola, cravado pelo racismo, intolerância e discriminação.

Embora representem iniciativas pontuais, há movimentos que tentam retirar as experiencias quilombolas do sertão alagoano de um cenário de aridez. Nesse sentido, o projeto de extensão Abí Axé Egbé, coordenado pelo professor Gustavo Manoel da Silva Gomes (2018), no campus Sertão, da Universidade Federal de Alagoas (UFAL), tenta dissociar a história e cultura negras do julgo racista e discriminatório, que perpassam o cotidiano sertanejo. O faz por meio das representações culturais negras, re-conhecidas a contrapelo. Por meio da arte, questionam-se os lugares de poder para reconstruir, com vigor, uma identidade étnica, emudecida por uma história de opressão,

problematizando temas, conceitos, valores e práticas; propondo novos referenciais sociais, culturais, políticos e históricos; experimentando novos conteúdos e formas na produção do conhecimento; buscando perceber e compreender o lugar e a ótica de identidades negras na sociedade brasileira; estimulando práticas curriculares "não-formais"; provocando uma educação pelos sentidos do corpo e pelos sentidos da fala, portanto, por uma educação 
estética: aquela que mexe com sentidos, sentimentos e saberes dos sujeitos envolvidos (GOMES, 2018, p. 24).

Assim, acreditamos que a função social da escola ganha corpo à medida que auxilia na desconstrução de assimetrias, no deslocamento de olhares hegemônicos, na diversidade e pluralidade culturais. Em tempos de fake news, xenofobia e racismo; de fortalecimento de ideologias conservadoras, autoritárias, neofascistas e neonazistas; de uma onda de sectarismo, que ganha as redes virtuais e espelha o mundo real, como a escola pode contribuir para a construção de pontes de aceitação à diversidade?

Os apontamentos de estudantes e professores do Ifal confirmam a ausência da questão quilombola na prática do currículo integrado, no âmbito do Ifal. Mais que unir conhecimentos teórico e práticos, e fortalecer o contato entre os saberes escolares, o currículo integrado precisa caminhar na direção da aceitação, da tolerância e do antirracismo. Nessa perspectiva, o reconhecimento das comunidades remanescentes quilombolas decerto pode remeter à escola um conhecimento tradicional, que apesar de silenciado, mantém-se vivo. No empenho por um currículo integrado e inclusivo, os Produtos Educacionais elaborados no âmbito dos Mestrados Profissionais vêm construindo um rastro de esperança para o questionamento das assimetrias, das desigualdades, e para a promoção de um ambiente social inclusivo e equitativo, auxiliando a reparar a negligência histórica a grupos sociais subalternizados.

\section{CURRÍCULO INTEGRADO E A QUESTÃO QUILOMBOLA: CONSTRUINDO UM PRODUTO EDUCACIONAL}

A ausência da questão quilombola nos Livros Didáticos e nos currículos da Educação Profissional e Tecnológica requer da comunidade educacional iniciativas que amparem as escolas no processo de inclusão dos saberes histórico-culturais dos povos de origem africana e afro-brasileira. Dentre as estratégias que vêm sendo elaboradas para a modificação desse quadro, destacam-se os Produtos Educacionais, que tem colaborado para a socialização dos saberes científicos, aproximando universidade, escola e comunidade. Aplicado em contexto real, o Produto Educacional é originalmente pensado para responder a uma necessidade percebida do ambiente escolar, aprimorando as práticas educativas. A despeito das críticas de que os Mestrados Profissionais reforçam o teor mecanicista da educação brasileira, 
vinculamo-nos ao pensamento de Rizzati, Mendonça, Mattos, Rôças, Silva, Cavalcanti e Oliveira (2020, p. 14):

Seria ingênuo de nossa parte pensar que todos os problemas da Educação Básica serão resolvidos por meio dos PE gerados nos PPG Profissionais. Entretanto, ao considerar a abrangência e localização desses programas, precisamos refletir sobre o impacto deles para a formação de professores/profissionais, na produção de pesquisas voltadas para diferentes contextos, além da mudança de postura sobre o processo de construção do conhecimento na sala de aula ou em espaços não formais.

Diante dessa necessidade, adentra às escolas e à EPT o uso da linguagem audiovisual, pensada como elo de articulação e de contextualização entre os saberes escritos e imagéticos, como uma via de facilitação para a aprendizagem e para a integração dos saberes no currículo. Apesar dessas possibilidades, limites e entraves da educação brasileira, como o minguado investimento em políticas de formação docente, transformaram o trabalho pedagógico audiovisual num artifício para preencher as lacunas, resultantes do descumprimento da programação escolar. Nessa direção:

\begin{abstract}
Alguns professores, para não falar a maioria, tratam à exibição dos filmes como um instrumento ilustrativo de temas ou como solução imediata para a falta de planejamento do dia. Em História, essa condição se mantém, haja vista que a profusão de produções épicas e temáticas são um enlevo para professores tradicionalistas, ainda presos aos livros didáticos e pouco preocupados com a capacidade analítica dos seus alunos e com a coerência dos filmes em relação aos conteúdos propostos pela disciplina. (FERRAZ, 2016, p. 8).
\end{abstract}

Na contramão dessa prática de ensino bancária (FREIRE, 1987), a utilização de recursos audiovisuais como materiais didáticos despontam como oportunidade de ampliação do conhecimento acerca da história e memória afro-brasileira e africana, em contexto nacional e local. Nessa mesma direção, podem auxiliar a preencher as lacunas deixadas pelo não cumprimento do ordenamento jurídico nacional, favorecendo a prática do currículo integrado no campo da Educação Profissional e Tecnológica. Atentamo-nos, assim, para a importância de "complementar os conhecimentos incluídos nos livros com informações e discussões referentes aos processos de construção dos conhecimentos" (MOREIRA, 2003, p. 24).

É nessa perspectiva que se justifica e se ancora a proposta de um vídeo educativo, apresentado como Produto Educacional no âmbito do ProfEPT/Ifal, cujo conteúdo versa 
acerca das memórias sociais de uma comunidade remanescente quilombola, no sertão alagoano, visando dar corpo ao debate quilombola na EPT. Nesse contexto, o vídeo será apresentado como uma porta de entrada às discussões quilombolas, na contracorrente de uma educação anti-emancipatória, acrítica e reprodutora de desigualdades. Assim, o vídeo pode auxiliar na compreensão das continuidades históricas das comunidades de resistência no horizonte do Brasil atual, tema ainda pouco tratado nos contextos do ensino de História, ante a carência de recursos didáticos que oportunizam aos docentes um debate qualificado. Nessa perspectiva, aproximamo-nos aos postulados de Antoni Zabala (1998) para pensar tal ferramenta pedagógica como um canal de aprendizagem ativa e significativa. Mas como docentes e estudantes percebem o vídeo? Enquanto ferramenta didático-pedagógica que favorece o diálogo ou como uma espécie de "tapa-buracos" na programação inicial do processo de ensino e aprendizagem?

À luz dos fatos, a potencialidade do uso didático dos vídeos educativos parece amparado pela difusão da internet e das redes sociais, cada vez mais alimentadas a partir da linguagem audiovisual. Essa percepção é reafirmada pelos discentes, que conferem à linguagem audiovisual características como didatismo, dinamicidade, clareza e contextualização, conforme Tabela 1:

Em sua acepção, o vídeo é compreendido como uma via de acesso para a construção de uma prática pedagógica plural, no conteúdo e na forma. Sob essa perspectiva, confirmamos a relevância do Produto Educacional, tendo em vista a valorização do recurso audiovisual pelos estudantes, de tal modo que 64\% deles afirmam que esse instrumento é extremamente importante, $12,9 \%$ muito importante e $19,4 \%$ importante.

Conforme expressa o Gráfico 1 (abaixo), os discentes também apresentam ampla aderência à proposta, tendo em vista que $91 \%$ deles concordam totalmente que o vídeo educativo é um recurso didático capaz de problematizar o lugar da memória quilombola na história brasileira. O panorama aqui elucidado justifica a construção do referido Produto Educacional, assentado na valorização das pessoas, dos espaços e das circunstâncias históricas da comunidade remanescente quilombola estudada (HALBWACHS, 2006). 
난

ISSN: $2594-4827$

\section{Tabela 1 - Estudante, justifique porque considera importante a utilização de vídeos como recursos didáticos nas aulas de História. ${ }^{4}$}

\begin{tabular}{|c|c|}
\hline Participante & Excerto/Depoimento \\
\hline E3 & $\begin{array}{l}\text { "Quanto mais ferramentas diferentes nas aulas, diferentes didáticas, } \\
\text { visuais, imagens, vídeos etc. Essas ferramentas interativas acabam } \\
\text { contribuindo para uma melhor experiência de ensino aprendizagem". }\end{array}$ \\
\hline E5 & $\begin{array}{c}\text { "Sim, haja vista que pode funcionar como um contato mais próximo ao } \\
\text { assunto, por ser visível, mas também por deixar as aulas mais } \\
\text { dinâmicas, contribuindo para o processo de aprendizagem". }\end{array}$ \\
\hline E7 & $\begin{array}{c}\text { "Vídeos auxiliam à nós alunos a ver as coisas com mais clareza, me } \\
\text { arrisco a afirmar que nos ajuda à sentir as coisas com eram/são de } \\
\text { fato". }\end{array}$ \\
\hline E20 & $\begin{array}{l}\text { "Geralmente vídeos contribuem para entendermos as palavras na } \\
\text { prática, sendo assim temos acesso a um estudo mais ilustrativo e } \\
\text { aprendemos com maior facilidade, creio eu que nosso cérebro tem } \\
\text { uma maior facilidade de assimilação das coisas". }\end{array}$ \\
\hline
\end{tabular}

Fonte: Dados da pesquisa (2020).

Compreendemos, assim, que as ferramentas audiovisuais, ao respeitarem o interesse dos estudantes, em sua maioria adolescentes, mantém conexão e diálogo aberto com os discentes. E, apesar das práticas educativas brasileiras ainda indicarem o descompasso da escola em relação ao uso das novas tecnologias audiovisuais, percebemos também nos docentes a anuência em relação à utilização do vídeo como forma de diversificar o debate e tornar o ensino de História inclusivo. Compreendem, portanto, que os recursos audiovisuais podem ocupar um lugar privilegiado nos processos de ensino e aprendizagem. Nessa mesma direção, conforme nos apresenta Moran (2007, p. 162), pensamos que tal cenário nos mostra que "precisamos (...) estabelecer pontes efetivas entre educadores e meios de comunicação".

\footnotetext{
${ }^{4}$ Com a finalidade de preservar a identidade dos participantes da pesquisa atribuímos a cada docente uma sigla que corresponde à letra do nome da categoria profissional seguida de um número que diz respeito à ordem das respostas dadas nos questionários. O mesmo critério foi adotado para os estudantes. Por exemplo: D1: a letra D está associada à docência e E está associada aos estudantes, e o número 1 corresponde a ordem de resposta dos questionários.
} 


\section{Gráfico 1 - Aderência dos estudantes ao vídeo educativo como inclusão do debate quilombola na formação.}

\section{VÍDEO EDUCATIVO É RECURSO CAPAZ DE PROBLEMATIZAR O LUGAR DA MEMÓRIA QUILOMBOLA NA HISTÓRIA BRASILEIRA.}

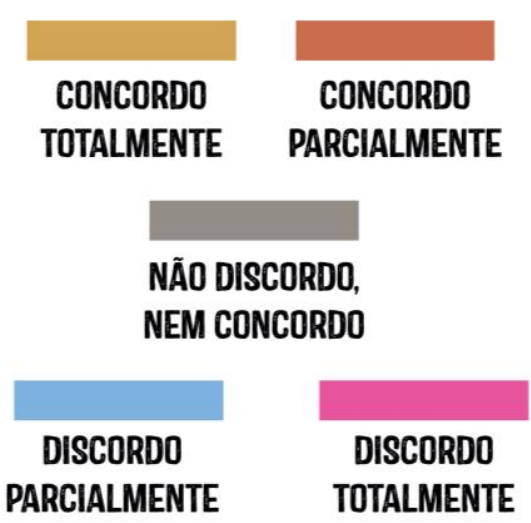

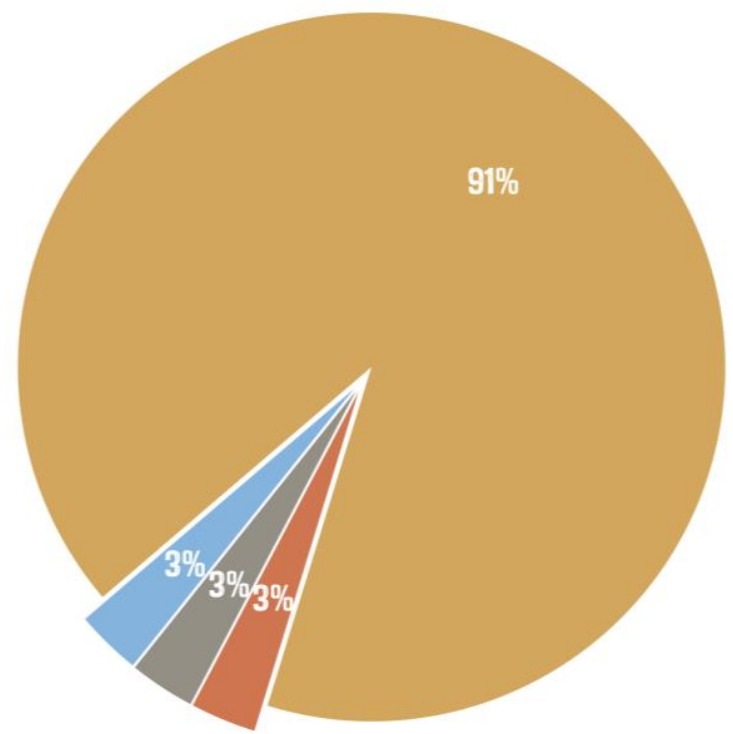

Fonte: Dados da pesquisa, 2020.

Kosik (2011) apresenta o trabalho pedagógico áudio-imagético como uma possibilidade para o estabelecimento de reflexões importantes, que ajudam a revelar, desmitificar e revolucionar as realidades ocultas. Nessa perspectiva, o audiovisual pode ser empregado como um mecanismo crítico e, ao mesmo tempo, sensorial, que, no caso da prática de currículo integrado, pode instigar mudanças de olhares racistas e discriminatórios. Em Moran (1995, p. 28), o audiovisual pode materializar uma aprendizagem transformadora porque é "sensorial, visual, linguagem falada, linguagem musical e escrita. (...). Somos atingidos por todos os sentidos e de todas as maneiras. O vídeo nos seduz, informa, entretém, projeta em outras realidades (no imaginário), em outros tempos e espaços."

O vídeo emerge como parte significativa de um processo maior de educação e mediação, recusando a reprodução do preconceito, questionando as estruturas racistas e desconstruindo estereótipos e estigmas sobre a população afro-brasileira, além de oportunizar debates transdisciplinares, globais e integrados. Frente à essa proposta, o corpo docente apresenta ampla aceitação ao Produto Educacional, conforme indica o Gráfico 2: 


\section{Gráfico 2 - Apreciação da temática pelo corpo discente, na percepção do corpo docente}

\section{CONTRIBUIÇÃO DO VÍDEO EDUCATIVO COMO RECURSO DIDÁTICO PARA O ENSINO DE HISTÓRIA QUILOMBOLA}

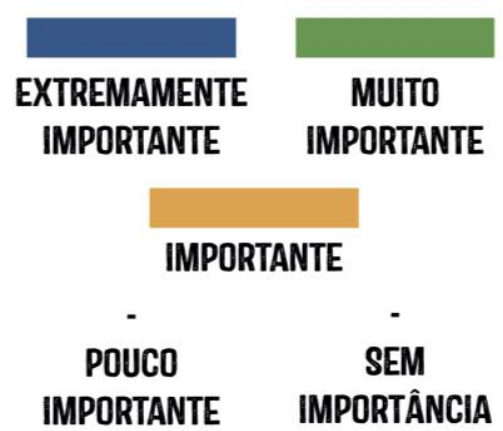

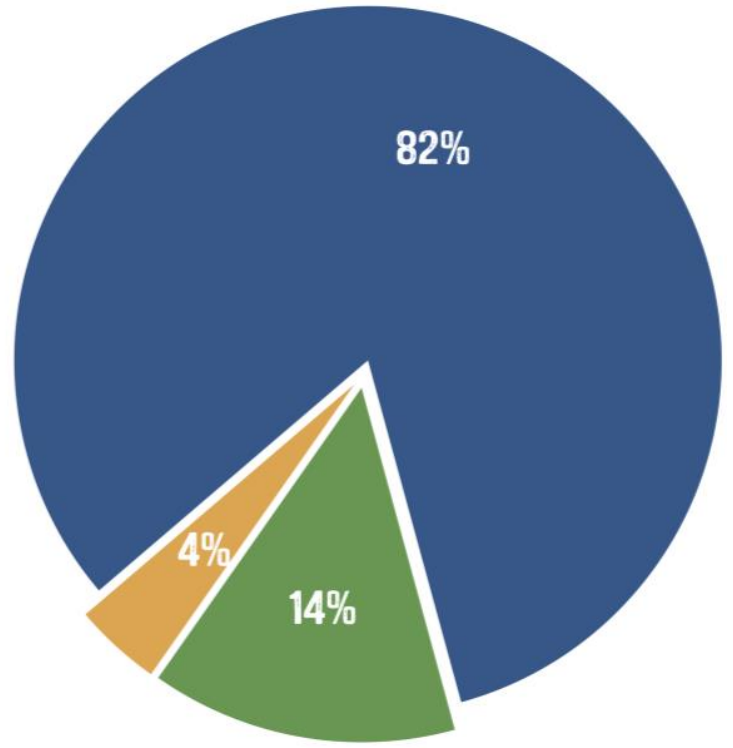

Fonte: Dados da pesquisa, 2020.

$\mathrm{Na}$ complexa arena de debates da educação brasileira, sobretudo na esfera da Educação Profissional e Tecnológica e seu compromisso com a formação integrada dos estudantes, o ensino da História assume papel de protagonismo na desconstrução de uma sociedade excludente, desigual e racista. Nesse trabalho, que precisa ser cada dia mais ativo e intenso nas escolas brasileiras, o vídeo como ferramenta didático-pedagógica pode colaborar para a (re)construção dos sentidos e significados da escola, concebendo-a como instrumento de produção e socialização dos conhecimentos, especialmente àqueles excluídos do currículo oficial. Uma "nova" forma de aprender, no entanto, enseja um novo comportamento dos atores envolvidos no processo de ensino e aprendizagem, de modo que o professor pode ter no vídeo educativo um aporte para práticas autônomas e humanistas. Por esse ângulo, acreditamos que:

trazer a tona uma discussão sobre uma prática escolar, amplamente difundida nas escolas brasileiras, é reivindicar que ela supere a ação usual e corriqueira de uma televisão ligada para preencher um horário vago, possibilitando que o uso das linguagens audiovisuais no cotidiano escolar seja de fato um momento de uma educação do olhar, do contemplar, de experiências estéticas e possibilidades de encontros com a diversidade, com diferentes narrativas e que possibilite a constituição de diferentes narrativas. (BERLE; MURILLO, 2011, p. 429). 
Nesse contexto, o vídeo educativo apresentará uma realidade invisibilizada no currículo oficial e nas práticas educativas, capaz de produzir, no universo formativo da EPT, debates acerca dos desafios enfrentados pelos remanescentes quilombolas no presente, das suas formas de re-existir no Brasil atual e das suas memórias vivas. Frente a esse compromisso, o participante D29 avalia positivamente a proposta de vídeo educativo,

[...] pois além de estar trazendo uma questão que durante muito tempo foi marginalizada no ensino de História, [...] está trazendo uma questão sobre Alagoas, aí você tem dois pontos positivos: a temática e a região e que podemos vira e mexe ter alunos dessas comunidades em sala de aula [...] Você imagine uma região que você está dando aula, que você tem um alunado que sabe que existe aquela comunidade, que muitos são daquela comunidade, então eles vão começar a se ver enquanto sujeitos históricos e vão se ver inseridos na história do Brasil. (D29, Dados da Pesquisa, 2020).

Assim, o Produto Educacional, fiel aos pressupostos teórico-metodológicos assumidos, tem um propósito bem definido: assegurar uma formação integrada, politécnica e omnilateral, que ultrapasse os padrões racistas que subalternizaram os povos quilombolas nas narrativas oficias e na história, devolvendo-lhes o protagonismo. Num horizonte democrático, é mister que a escola atue no sentido de colaborar para a superação da exclusão e hostilidade de toda natureza que ainda alcança a população negra quilombola após mais de três séculos de escravidão.

\section{CONSIDERAÇÕES FINAIS}

No decorrer deste texto, refletimos a importância da inclusão da questão quilombola no universo formativo da Educação Profissional e Tecnológica, à luz dos compromissos mais recentes assumidos pela modalidade de ensino, que asseguram uma formação omnilateral, assentada na prática do currículo integrado.

Nesse sentido, compreendemos que o ensino de História ganha contornos outros diante da necessidade de repensar as práticas curriculares, especialmente no âmbito dos Institutos Federais, que assumem como premissa a valorização da diversidade e a diminuição das desigualdades. Nesse contexto, o ensino de História pode atuar para dar voz a sujeitos 
invisibilizados, como os remanescentes quilombolas, explorando uma plêiade de fecundos instrumentos historiográficos, que cooperam para o trabalho pedagógico diverso, plural, multiétnico e inclusivo, a exemplo dos olhares advindos da Nova História, da história vista de baixo e da história oral.

Enovelado pelos olhares plurais da História, o currículo da EPT pode frear o imobilismo que pôs a história e memória quilombola subalterna diante de hegemonia de narrativas contadas na perspectiva eurocêntrica. Nesse contexto, a manutenção do cenário de ausência da questão quilombola, retratado por estudantes e docentes do Ifal, e representado na incipiência desse debate nos Livros Didáticos, exige um rearranjo do lugar afro-brasileiro no currículo, sobretudo como condição sine qua non para a prática efetiva do currículo integrado, um dos mais realçados objetivos da EPT no Brasil.

Na construção do currículo integrado, compreendido também como uma experiência de integração e valorização das culturas negadas e silenciadas no cotidiano histórico-social, refletimos a fecundidade didático-pedagógica do vídeo educativo, apresentado como Produto Educacional no âmbito do ProfEPT/Ifal, no esforço de trazer a história e cultura quilombolas para o contexto formativo da EPT. Nessa direção, a aderência de estudantes e professores à linguagem audiovisual, demonstrada por meio da pesquisa-ação, reafirma a relevância do vídeo educativo, na promoção de uma formação integrada, que se aproxime dos centros de interesse dos aprendizes mediante o estabelecimento de uma relação dialógica e reflexiva.

Por fim, lembramos que a presente pesquisa parte de uma amostra que, no contexto da pesquisa-ação, revela-se significativa, mas representa singularidades que devem ser observadas. Nesse sentido, acreditamos ser urgente que o campo científico se debruce sobre a ausência da questão quilombola no currículo e amplie as investigações acerca dessa problemática, sobretudo pensando estratégias para vincular a produção acadêmica à vivência escolar, propiciando um ensino que valorize a identidade e trajetória dos povos quilombolas na formação brasileira.

\section{REFERÊNCIAS}

BARDIN, Laurence. Análise de conteúdo. São Paulo: Edições 70, 2011. 
BERLE, Simone; MURILLO, Márcia Vilma. A linguagem audiovisual como prática escolar. Signo, Santa Cruz do Sul, v. 36, n. 61, p. 422-439, jul. 2011. ISSN 1982-2014. Disponível em: https://online.unisc.br/seer/index.php/signo/article/view/2141 . Acesso em: 11 set. 2020.

BERNSTEIN, Bernstein. A estruturação do discurso pedagógico: classe, códigos e controle. Petrópolis: Vozes, 1996.

BRASIL. Ministério da Educação. Diretrizes curriculares nacionais para a educação das relações étnico-raciais e para o ensino de História e Cultura Afro-brasileira e Africana. Brasília: Ministério da Educação, 2004. Disponível em http://portal.mec.gov.br/escola-de-gestores-da-educacao-basica/323-secretarias-

$\underline{112877938 / \text { orgaos-vinculados-82187207/12988-pareceres-e-resolucoes-sobre-educacao-das- }}$ relacoes-etnico-raciais. Acesso em: 15 mar. 2020.

CASTILHO, Fábio Francisco de Almeida. Escravidão e violência: crimes cometidos por escravizados no interior de Alagoas no final do século XIX em uma perspectiva da prática de jaguncismo. Opsis, v. 18, n. 2, 19 nov. 2018. Disponível em: https://www.revistas.ufg.br/Opsis/article/view/48731 Acesso em: 12 out. 2020.

CIAVATTA, Maria; RAMOS, Marise Nogueira. Ensino Médio e Educação Profissional no Brasil: Dualidade e fragmentação. Revista Retratos da Escola, Brasília, v. 5, n. 8, p. 27-41, jan./jun. 2011.

Disponível em: http://retratosdaescola.emnuvens.com.br/rde/article/view/45/42. Acesso em: 11 jan. 2020.

FERRAZ, Liz Motta. História e Cinema: Luz, Câmera, Transposição Didática. O olho da história, ano 12, n. 9, Dez. 2006. Disponível em: http://oolhodahistoria.ufba.br/wpcontent/uploads/2016/03/lizmotta.pdf Acesso em 28 out. 2020.

FREIRE, Paulo. Pedagogia do oprimido.Rio de Janeiro: Paz e terra, 1987.

FRIGOTTO, Gaudêncio; CIAVATTA, Maria; RAMOS, Marise. Ensino médio integrado: concepções e contradições. São Paulo: Cortez, 2005.

GRAMSCI, Antonio. Os intelectuais e a organização da cultura. São Paulo: Circulo do livro, 1998.

GOMES, Flávio dos Santos. Mocambos e quilombos: uma história do campesinato negro no Brasil. São Paulo: Claro Enigma, 2015.

GOMES, Gustavo Manoel da Silva. Extensão acadêmica, cultura afro-brasileira e ensino de História: interações éticas e estéticas de uma experiência sertaneja. Revista Extensão, v. 2, n. 1, 2018. Disponível em: https://revista.unitins.br/index.php/extensao/article/view/1067 Acesso em: 22 out. 2020.

HALBWACHS, Maurice. A memória coletiva. São Paulo: Centauro, 2006. 
ITERAL.Instituto de Terras e Reforma Agrária de Alagoas. Página inicial. Disponível em: http://www.iteral.al.gov.br/dtpaf/comunidades-quilombolas-de-alagoas/comunidadesquilombolas-de-alagoas. Acesso em: 20 de jul. de 2020.

MARQUES, Danilo Luiz. Sob a "sombra" de Palmares: escravidão e resistência no século XIX. São Paulo: e-Manuscrito, 2020.

MINAYO, Maria Cecília de Souza. (Org). Pesquisa social: teoria, método e criatividade. $21^{\circ}$ ed. Petrópolis: Vozes, 2002.

MORAN, José Manuel. O vídeo na sala de aula. Comunicacão e Educacão, São Paulo, v.2, p.27-35, jan./abr. $1995 . \quad$ Disponível em: http://www.revistas.usp.br/comueduc/article/view/36131. Acesso em: 29 jun. 2017.

MOREIRA, Antonio Flavio Barbosa. Indagações sobre currículo: currículo, conhecimento e cultura/[Antônio Flávio Barbosa Moreira ,Vera Maria Candau] ; organização do documento Jeanete Beauchamp, Sandra Denise Pagel, Aricélia Ribeiro do Nascimento. - Brasília : Ministério da Educação, Secretaria de Educação Básica, 2007.

MOURA, Clóvis. Quilombos - resistência ao escravismo. São Paulo: Ática, 1993.

NOSELLA, Paolo. Ensino médio: em busca do princípio pedagógico. Educ. Soc., Campinas, v. 32, n. 117, pág. 1051-1066, dezembro de 2011. Disponível em http://www.scielo.br/scielo.php?script=sci arttext\&pid=S010173302011000400009\&lng=en\&nrm=iso . acesso em 18 de setembro de 2020 . .

RAMOS, Igor Guedes. Genealogia de uma operação historiográfica: Edward Palmer Thompson, Michael Focault e os historiadores brasileiros da década de 1980. São Paulo: Cultura Acadêmica, 2015.

RAMOS, Marise Nogueira. A pedagogia das competências: autonomia ou adaptação? São Paulo: Cortez, 2001.

REIS, João José; SILVA, Eduardo. Negociações e Conflito; a resistência negra no Brasil escravista. São Paulo: Companhia das Letras, 2005.

RICOEUR, Paul. A memória, a história, o esquecimento. Campinas: Unicamp, 2007.

RIZZATTI, Ivanise Maria; MENDONÇA, Andrea Pereira; MATTOS, Francisco; RÔÇAS, Giselle; SILVA, Marcos André B. Vaz da; CAVALCANTI, Ricardo Jorge de Souza; OLIVEIRA, Rosimary Rodrigues de. Os produtos e processos educacionais dos programas de pós-graduação profissionais: proposições de um grupo de colaboradores. ACTIO, Curitiba, v. 5, n. $2, \quad$ p. 1-17, mai./ago. 2020. Disponível em: https://periodicos.utfpr.edu.br/actio/article/view/12657. Acesso em: 10 set. 2020.

SAMUEL, Raphael. História Local e História Oral. Revista Brasileira de História. pp. 219242. V. 9, n. ${ }^{\circ}$ 19, set. 1989 / fev. 1990. 
SANTOMÉ, Jurjo Torres. Globalização e interdisciplinaridade.Porto Alegre: Artes Médicas, 1998.

SAVIANI, Demerval. Sobre a concepção de politecnia. Rio de Janeiro: Politécnico de Saúde Joaquim Venâncio/Fiocruz, 1989.

SCHMITT, Alessandra; TURATTI, Maria Cecília Manzoli; CARVALHO, Maria Celina Pereira de. A atualização do conceito de quilombo: identidade e território nas definições teóricas. Ambiente. soc., Campinas, n.10, pág. 129-136, junho de 2002. Disponível em http://www.scielo.br/scielo.php?script=sci arttext\&pid=S1414-

753X2002000100008\&lng=en\&nrm=iso. Acesso em 15 de outubro de 2020.

SILVA, Egnaldo Rocha da.Comunidade negra rural de Lagoa Santa: história, memória e luta pelo acesso e permanência na terra (1950-2011) 2013. Tese (Doutorado em História) Programa de Pós-Graduação em História, Pontifícia Universidade Católica de São Paulo, São Paulo, 2013.

SOUZA, Laura Olivieri Carneiro de. Quilombos: identidade e história.Rio de Janeiro: Nova Fronteira, 2012.

THIOLLENT, Michel. Metodologia da pesquisa-ação. São Paulo: Cortez, 1986.

THOMPSON, Paul. A voz do passado - história oral. 3ª ed. São Paulo: Paz e Terra, 1992.

ZABALA, Antoni. A prática educativa: como ensinar. Porto Alegre: Artmed, 1998. 